\title{
Ronald de Carvalho
}

No dia quinze de fevereiro de 1935 , um trágico acidente de autoI móvel, em pleno centro do Rio de Janeiro, veio a extinguir a existência dum dos maiores vultos da literatura brasileira, Ronald de Carvalho. Nasceu nessa mesma cidade quarenta-e-dois anos antes, no dia dezesseis de maio de 1893. A sua vida expandiuse com rapidez e com extensão. Antes de chegar aos veinte anos já se formara em direito pela Faculdade Livre de Ciências Jurídicas e Sociais da capital. Viajou por muitos países europeus, incluindo Portugal, onde conheceu alguns dos poetas que fundaram a revista Orfeu - Luis de Montalvor, Mário de Sá Carneiro, Fernando Pessoa. Mais tarde as suas viagens levaram-no por todo o Hemisfério Ocidental. Ainda jovem, entrou no serviço diplomático onde avançou ràpidamente, servindo a pátria nas embaixadas em Paris e na Haia. Servia como secretário ao Presidente da República quando foi vítima do desastre. É certo que a morte de Carvalho roubou ao Brasil um dos seus espíritos mais brilhantes.

Carvalho começou com sonetos do cunho parnasiano e simbolista, Luz gloriosa (1913) e Poemas e sonetos (1919). Isto era natural. Para o Brasil, a França era o coração da cultura moderna. Naquêle tempo os modelos franceses da educação, música e poesia eram os modelos naturais não só para o Brasil, mas também para os outros países latino-americanos. Os poemas dêstes dois primeiros livros de Carvalho têm grande mérito em si, mas a maior importância está na disciplina métrica que forneceram ao autor. $O$ poeta nunca esquece por completo o aticismo da forma e a pureza do estilo destas primeiras obras; ainda se pode ver a preponderância destas duas escolas nos seus poemas escritos quando era considerado um dos chefes da escola modernista brasileira. Mesmo quando volta a te- 
mas brasileiros, raras vêzes abandona a objetividade e a perfeição dos seus modelos franceses. Só a influência de Walt Whitman, que chegou mais tarde, parece ter actuado sôbre a sua poesia dum modo significativo. Mas Whitman nunca induziu Carvalho a renunciar à palavra selecta, ao verso claro. E curioso notar que Carvalho rebelouse conscientemente contra os temas franceses mas continuou inconscientemente a empregar na sua poesia a elegância fina e delicada dessa tradição.

Com os seus amigos Graça Aranha, Mário de Andrade e Oswald de Andrade participou da Semana de Arte Moderna, quando proclamaram a nova escola da poesia brasileira no ano de 1922. Estes escritores decidiram procurar no seu próprio país -o Brasil- a sua inspiração. Cantaram o amor da pátria. Vangloriaram-se do patriotismo intenso e duma liberdade que os livrasse da tradição literária européia. Desejavam esta liberdade, diz Carvalho, porque "A arte é uma aspiração à liberdade. O que nós, poetas, músicos, pintores, escultores e arquitetos desejamos é criar o nosso ritmo pessoal, é transmitir a nossa harmonia interior. Cada um de nós é um instrumento por onde passa a corrente da vida. Não queremos regras nem admitimos preconceitos. Não nos atraem as teorias especiosas." Desaparece a maior parte das estâncias poéticas formais, sobretudo o soneto. Em lugar destas estabelece-se uma liberdade quási completa de metros, ritmo e forma. Os temas refletem o que vê e sente o autor, porque, como expóe Carvalho, "A obra de arte não repete, mas adivinha e transforma a Natureza. O artista é um transfigurador. Recebe a energia da vida e, em troca, lhe dá a forma."

Em Epigramas irônicos e sentimentais, aparecido em 1922, Carvalho exprime poèticamente estas idéias num poema intitulado "Teoria", no qual anima o poeta a criar o seu ritmo a cada momento: "Não esgotes jamais a fonte da tua poesia, / enche a bilha de barro ou o cântaro de granito / com o sangue da tua carne e as vozes do teu espírito!" E conclui, "Cria o teu ritmo e criarás o mundo!" Em "Arte poética" crê que a inspiração poética vem, em fim, do coração:

ARTE POETICA

Olha a vida, primeiro, longamente, enternecidamente, como quem a quer adivinhar... 
Olha a vida, rindo ou chorando, frente a frente.

Deixa, depois, o coração falar.

Em geral, os poemas desta coleção ou proclamam a filosofia epicuréia de Omar Khayyám ou descrevem paisagens brasileiras. Num poema chamado "Rubayat" aconselha-nos a viver: "Vive, irmão! / Vive, que a vida passa... / Canta! / que a terra é fria e silenciosa..." Outro poema, "Ode", reforça esta filosofia:

ODE

Enquanto nos altos ramos

a cigarra ainda rechina,

enquanto há sol de verão

pelo caminho,

vamos,

Escansão!

a hora é divina,

enche meu copo de vinho...

Carvalho demonstra um entendimiento extremamente sensitivo ao descrever a sua pátria - um pincel fíno com cores brandas $\mathrm{e}$ quentes que criam imagens finas e delicadas. As cenas brasileiras podem ser, algumas vêzes, concretas, com descrições detalhadas da fauna e flora brasileiras ou, outras vêzes; sómente um "mood" brasileiro. Porém, em todos os poemas há cuidado na linguagem, felicidade na cadência, frutos da sua herança parnasiana e simbolista:

SONHO DE UMA NOITE DE VERAO

Louca mariposa bate na vidraça.

Vem da noite enorme,

Vem da noite morna cheia de perfumes.

Fóra, tudo dorme...

Que silêncio enorme!

Rondam pelas moitas leves vagalumes.

Louca mariposa bate na vidraça.

Como as horas fogem, como a vida passa...

Tôda a América foi escrito durante as viagens do autor pelo Hemisfério Ocidental durante os anos de 1923 e 1924. Foi publicado dois anos depois, no ano de 1926. Neste livro há uma alteração no- 
tável na forma. O que era dantes sucinto torna-se rapsódico. O que era claro e ático mantém o aticismo mas ajunta a variedade; mantém a perfeição mas ajunta a extensão. O livro, que reflete Walt Whitman, tornou-se popular instantâneamente. Tôda a América foi traduzido para o espanhol (1930) pelo poeta menor do modernismo, Francisco Villaespesa e também para o italiano (1933) por Agenore Magno. No seu prólogo Villaespesa declara, "Si nuestra América pudiese tener un poeta integralmente representativo, y la juventud precisase de un Maestro que la orientase, yo no vacilaría en dar ambos títulos... al joven autor de este libro." O que encantou os leitores e ao mesmo tempo os editores foi a vitalidade e o alcance do livro; aliás, acharam nos seus catálogos à manera de Whitman, nos seus péans, na sua aceitação universal e nas suas afirmações o sentido do espaço, vigor e otimismo que sentiam como cidadóes dum novo e vasto continente.

No poema de advertência, Carvalho dirige-se ao europeu que, segundo o poeta, não sabe exatamente o que querdizer "americano" (Carvalho emprega a palavra "americano" para indicar qualquer habitante do Novo Mundo): "Europeu! filho da obediência, da economia e do bom-senso, / tu não sabes o que é ser americano!" Depois, oferece com afectuosidade o primeiro poema ao seu país natal, o Brasil. Em realidade o livro abarca todo o hemisfério; o volume inclui poesias sôbre as várias ilhas do Mar das Caraíbas, o Peru, o Chile, a Argentina, o México e os Estados Unidos. Os temas são também diversos, tratando das condições sociais, estéticas e políticas. Celebra as grandes liberdades do Novo Mundo: "América livre do terror! / América voltada para o futuro como um botão que espera a flor e o fruto." Dedica as suas canções a "América de tôdas as imaginações, do azteca e do germano, do guarani e do latino, do hispano e do inca, do aimoré e do saxão, do eslavo e do africano" - com as suas pirâmides, os seus arranha-céus, as suas pedras de sacrifício e os seus calendários, os seus pronunciamentos e a sua boa fé puritana. Há um catálogo das regiōes: rios, cachoeiras, montanhas, chãs, planaltos, várzeas, angras, praias, florestas, cafèzais, seringais, canaviais, óleos, metais, pedrarias; o comércio e a indústria; as escolas e as bibliotecas; a cultura e a barbárie. Em ritmos ousados e livres traça o desenvolvimento histórico da civilização americanaas terras indomadas, o ímpeto americano, a coragem das suas aspi- 
rações e o futuro glorioso da sua civilização. Carvalho possui um conhecimento profundo do hemisfério. Há um sensualismo viril e voluptuoso emanando dos seus poemas, revelando a riqueza e atracção luxuosa do hemisfério virgem: "a manhã é um canto, é uma palpitação, um estrondo, um rumor, um grito alegre de posse"; "do sexo imenso da terra jorram metais, óleos, pedrarias"; os canaviais "estalam e se derretem en pingos de mel"; e as matas "chiam, trilam, assobiam e fervem." Nos grandes silêncios dos Andes é que o poeta sente a América:

\section{PUENTE DEL INCA}

Aqui está a tua virgindade cheia de promessas excitantes, aqui, onde o imigrante passa de olhos inocentes, onde o homem do Báltico e o homem do Adriático, o homem do Reno e o homem do Guadalquivir não sabem as sementes que devem semear.

Oh! América, o teu dia será primitivo, e será fresco e ingénuo, e flutuará sôbre as águas como aquêle outro dia que, o espírito efémero entenebreceu. Aqui nestas solidões brutas é que eu te sinto, América! Aqui está a tua virgindade, a tua virgindade que não podemos fecundar! Ah! como será bela a dansa do homem livre, que ainda esperas, a dansa do homem livre sôbre o teu ventre violado...

Carvalho elogia a música do hemisfério: banjo, guitarra, maracà, violão, torocaná, quena e marimba; o ritmo vertiginoso de batuques, jongos, tangos, maxixes, jarabes, cuecas, cateretês.

O poema "Broadway" representa os Estados Unidos. "Broadway" exprime com exactidão o carácter vasto e generoso do volume. Reflete também o estilo característico de Whitman - paralelismo, distribuição em tábuas, repetição, e uma elevada nota rapsódica. A poesia, acreditava Whitman, deveria nombrar as riquezas do mundo, evocando assim a coisa e a sua essência. Em "Broadway" vê-se claramente os ditados do poeta norte-americano:

BROADWAY

Chato, pardo-cinzento, o chão flutua lento, mole, o chão escorre vagaroso, contrae-se em blocos súbitos, 
estica-se em flechas longas, trepidantes, dispara, de repente, em riscos elásticos,

gira, rodopia, turbilhona e ferve num vapor sutil de linhas e movimentos.

Aquêle chão carrega tôdas as imaginações do mundo!

Aquêle chấo carrega

isbas da Ucrânia, vinhas de Bordeus, parques do Tâmisa, saveiros do Volga, ámbar, corais, madréporas das Antilhas, guano de Mollendo, canaviais de Cuba, juncos de Xangai, cafèzais de Ribeirão Preto, chifres do Pampa, fornos de Essen, fornos de Newcastle, óleos de Tampico, salitres de Iquique, barbatanas de Terra-Nova, mares coalhados de ferros e madeiras, terras gotdas, ilhas com batuques, tan-tans e rêdes molinhosas, montanhas verdes, montanhas de óxidos e cristais, rios onde boiam troncos, plantas, cobras e tartarugas, florestas de plumas, penas e folhagens, praias, canais, mangues, luzes do trópico, luzes do polo, desertos, civilizações ...

Aquêle chão é uma paisagem em marcha.

Chão qú mistura as poeiras do Universo e onde se confundem todos os ritmog do passo humano!

Chão épico, chão lírico, chão idealista, chão indiferente de Broadway, largo, chato, prático e simples como este roof liso, suspenso no ar, èste roof, onde um saxofone derrama um morno torpor de senzala debaixo do sol.

Em Tôda a América nota-se fàcilmente a dívida de Carvalho a Whitman. De todos os poetas brasileiros que imitaram Whitman (como Menotti del Picchia) Carvalho é tal vez o que alcançou melhor êxito. Carvalho, como Whitman, possui um rico sentimento democrático, enumera nos seus versos todo o nível social da vida, re- 
gosija-se com a abundância do mundo. Leaves of Grass de Whitman, publicado em 1855, marca tuma época na poesia das Américas, embora a sua influência no Brasil fôsse demorada até à renascença patriótica que deflagrou com o movimento modernista durante a Semana de Arte Moderna. No prefácio de Leaves of Grass, Whitman declara que na grande população e nas vastas terras novas do oeste jaz a inspiração poética mais extensa. O poeta, continua Whitman, deve amar o mundo natural, avaliar as riquezas dêle e celebrá-las. Enquanto à forma, rejeitou as estâncias tradicionais e os metros estabelecidos. Segundo Whitman, o verso deve ser controlado pela idéia expressada, e o ritmo é livre, emancipado de qualquer premeditada regra de medida. E criado pela idéia proferida. Nisto Carvalho é discípulo de Whitman, e juntos os dois têm influido no tema e técnica de muita poesia ibero-americana.

É interessante comparar "Broadway" de Carvalho com os versos de Whitman sôbre New York, tirados de "Crossing Brooklyn Ferry." Cruzando o rio, Whitman diz, viu mutitas vêzes atracarem navios nos portos:

The roud masts, the swinging motion of the hulls, the slender serpentine pennants,

The large and small steamers in motion, the pilots in their pilot-houses,

The white wake left by the passage, the quick tremulous whirl of the wheels, The flags of all nations, the falling of them at sunset,

The scallop-edged waves in the twilight, the ladled cups, the frolicsome crests and glistening,

The stretch afar growing dimmer and dimmer, the grey walls of the granite storehouse by the docks...

On the neighboring shore, the fire from the foundry chimneys burning high and glaringly into the night, Casting their flicker of black contrasted with wild red and yellow light over the tops of houses, and down into the clefts of streets.

Os versos de Carvalho são menos compridos do que os de Whitman nesta seleção mas é instrutivo notar que os seus versos também acabam em vírgulas como os de Whitman, e os últimos versos de Carvalho, como os de Whitman, elevam-se a uma comprida pronunciação lírica. Num poema intitulado "A Broadway Pageant", Whitman defato proclama New York o centro de tôdas as culturas e de 
todos os povos. "Superb-faced Manhattan!... to us, then at last the Orient comes." O poeta vê na cidade :

Mandarin, farmer, merchant, mechanic, and fisherman,

The singing-girl and the dancing-girl, the ecstatic persons, the secluded emperors, Confucius himself, the great poets and heroes, the warriors, the castes, all.

$O$ verso de Carvalho é sòmente reflexão do de Whitman: "Aquêle chão carrega tôdas as imaginações do mundo!"

Dentre o tema e a forma de Whitman aparece de vez em quando em Tôda a América a herança fundamental da juventude francesa de Carvalho. Típico da perfeição francesa e da liberdade de Whitman é êste poema duma índia na Avenida Juárez da capital mexicana. Carvalho gostava imensamente do México onde passou algum tempo como hóspede de honra. Este volume inclui um grande número de poemas sôbre o México como:

$$
\operatorname{MEXICO}(D, F .)
$$

A índia que passa tôdas as manhãs, sob a minha janela, a índia da Avenida Juárez, como é feliz!

Leva nas mäos a brasa dos sarapes, na cabeça o rebozo de seda "de una niña muy bien", nos pés as sandálias de tações duros, para riscar o jarabe, e na boca a última canção tapatia.

India da Avenida Juárez, tôda florida de ritmos, tu és o México, ou Deus não existe.

Descrevendo o norte seco do México Carvalho escreve:

FRONTEIRA DO RIO GRANDE

Fervura de areiais,

Cardos.

Cardos.

Magueyes.

Pedras

que se levantam e rompen o horizonte.

Chão de cintilações.

Silêncios vigiados,

homens por trás de todos os silêncios... 
Campainhas de cabras.

Fogo de sarapes.

México!

No ano de 1926 apareceu a última coleção de poesias de Carvalho, Jogos pueris. Estes poemas continuam a orientaçẫo modernista começada em Epigramas irônicos e sentimentais. Acha-se o erotismo dos trópicos nesta poesia. O poema que segue é um exemplo admirável. Atribuindo sensualidade à luz e à árvore, aos ramos e às fôlhas, Carvalho escreve um curto poema de exuberância notável:

\section{ANTROPOMORFISMO}

A luz sinuosa sôbre os troncos duros.

De ramo em ramo as fôlhas tôdas se lambem, linguas trêmulas, breves, céleres batendo!

- Escorre mel do ar...

As mãos do vento baixam sôbre o corpo moreno da terra áspera, excitante.

No silêncio morno, fatigado, vertiginoso, caem gotas pesadas de resina pelo chão...

Ronald de Carvalho goza duma alta fama no Brasil como poeta e também como crítico. A sua Pequena história da literatura brasilei$r a$, pequena só no título, continua a ser usada como compêndio nas escolas brasileiras. $\mathrm{E}$ considerada uma das melhores histórias da literatura brasileira. Como poeta Carvalho une e assimila duas famosas tradiçôes poéticas. Quando chefe do movimento patriótico manifestou uma coalescência curiosa dos elementos europeus e americanos - a forma pura dos parnasianos e a qualidade musical e rítmica das palavras e das imagens dos simbolistas, junto à liberdade literária aclamada pelos modernistas do Brasil e simbolizada por Walt Whitman. Os modernos poetas brasileiros devem muito a Carvalho e aos outros poetas modernistas que lhes deram a liberdade literária que hoje existe, porque êstes poetas abriram caminho para uma poesia pessoal e ática ao mesmo tempo- uma poesia que representa genuinamente as palpitantes emoções do novo Brasil.

Albert R. Lopes,

WILlis D. JACOBS, Universidad de Nuevo México, Albuquerque, Nuevo México. 
